\title{
INVESTIGATION OF FILTRATION CAPACITY OF SURFACE WASTEWATER FILTERS BY MATHEMATICAL MODELLING
}

\begin{abstract}
As the urbanisation level increases, due to intensification of car traffic and increased areas of impermeable surfaces, pollution of surface wastewater and a negative impact on water bodies are increasing. Due to the increasing pollution of surface water bodies, the eutrophication process is taking place intensively. One of the technologies of surface wastewater treatment allowing reduction in the amounts of suspended solids (SS), heavy metals and other pollutants is surface wastewater filters. Filters with different fillers have been designed for the treatment of principal surface wastewater pollutants: suspended solids, heavy metals (zinc, cadmium, copper, lead), $\mathrm{BOD}_{5}$, total carbon and nitrogen. The Kriging method was adapted to test the efficiency of filters filled with construction waste and wood waste-derived biochar using distance matrices. The method developed makes it possible to model the characteristics of filters in relation to different fillers, using experimental results. The mathematical model is suitable for other filtrate characteristics, not only the ratio of fillers, but also the length of the filter life, its durability calculations, which allows optimizing filter cleaning efficiency up to $96.93 \%$.
\end{abstract}

Keywords: design of experiments, Kriging method, Gaussian random fields, surface wastewater treatment, response surface, distance matrices

\section{Introduction}

Improper cleaning of surface wastewater threatens water quality. As the urbanisation level increases, due to intensification of car traffic and increased areas of impermeable surfaces, pollution of surface wastewater and a negative impact on water bodies are increasing. The urbanisation process increases the diversity and quantity of pollutants entering water bodies $[1,2]$. As cities grow, traffic congestion is increasing, green areas are decreasing, i.e., less wastewater is infiltrated into the ground and more of it enters the streets causing the accumulation of environmentally hazardous pollutants [3]. Surface wastewater treatment is essential and important for protecting the natural environment from adverse effects. In order to address the problems encountered, considering the current state of surface wastewater management in urban areas, it is necessary to plan and use measures to create an economical, technical and efficient system of urban wastewater management $[4,5]$.

In recent years, environmental pollution has been a matter of particular concern, therefore, developed countries make efforts to use wastewater treatment methods which are acceptable in terms of ecology, technology, usage and cost.

\footnotetext{
${ }^{1}$ Vilnius Gediminas Technical University, Saulètekio 11, 10221 Vilnius, Lithuania

2 Vilniaus kolegija/University of Applied Sciences, J. Jasinskio 15. LT-01111, Vilnius, Lithuania

*Corresponding author: egle.marciulaitiene@vgtu.lt
} 
As the requirements for wastewater treatment quality in terms of biogenic and organic materials are tightened, it is very important to find a reliable and inexpensive wastewater treatment method that will allow the desired results and reduce the cost of purification equipment. By properly installing and using filters filled with construction waste and biochar, there is a possibility to reduce operating costs and achieve the desired results in terms of treatment quality.

Surface wastewater treatment technologies and methods include: sedimentation, filtration, adsorption, infiltration, microorganism activity, remediation, etc. [6, 7]. Filtration is a process during which many of the complex pollutants are physically deformed and separated when wastewater is passed through a layer of filtration sand or other mineral material, a layer of soil and other organic materials, and is retained on the surface or in the pores of filtration media. The efficiency of filtration can be very high. For example, it has been found that more than $90 \%$ of fine particles $(6-41 \mu \mathrm{m}$ in size) found in surface wastewater is retained within a sand layer of $45 \mathrm{~cm}$, and even greater efficiency is achieved by treating particles larger than $41 \mu \mathrm{m}$ [7]. Filtration is not effective in treating dissolved pollutants in wastewater. The benefit of the filtering method is the greater, the more functionally suitable (filter filling) material is chosen. Relatively dense materials, like soil or sand, are very important for filtration, while more porous materials, like compost or peat, provide less benefit to filtration efficiency [7].

The ability of a filtration system to remove dissolved plant nutrients, heavy metals or organic pollutants is most often indicated by adsorption, whereby ions and molecules enter adsorbent pores. In general, the potential benefits of filtering adsorption are evident when filter media contains a large proportion of organic materials or clay, and a large cation exchange capacity in neutral or alkaline medium [6]. Each media used in filtration systems exhibits a different adsorption potential. For example, at the beginning of treatment sand contains no organic materials and clay, so its adsorption potential is considered low. Over time, most sand filters are coated with a thin layer of organic film at the top of filtration material, due to deposited materials, thus the adsorption potential is increased. Organic filter material, such as soil, peat and compost, has a higher adsorption potential, if the adsorbate has a $\mathrm{pH}$ value of about 7 [6].

The filtering characteristics of filter fillers are defined by their surface area; the larger the surface area per unit volume, the better the conditions for the biofilm formation, and the characteristics also depend on their density, roughness, porosity, durability, moisture retention, etc. [8]. Ideally, filter filler should be characterised by a high specific surface area, long lifetime (over time, it does not clog) and low cost. Taking into account the abovementioned conditions, filter materials (filter fillers) are selected and produced from waste (aerated concrete waste, stone wool waste and wood waste-derived biochar). The main advantage of waste materials is low cost and low need for processing. Factors such as cost, environmental impact, disposal and flexibility of application were taken into account when selecting filter filling materials [9]. When using waste as a filtering material, account is taken of the waste management hierarchy, a waste reduction and reuse strategy is followed that reflects the sustainable management of urban rainwater [10].

Mathematical modelling of wastewater treatment processes has become increasingly popular in recent years [11-14]. Usually wastewater filters are complex systems, mathematical modelling of which is most often carried out using the difference differential models, which require complicated mathematical tools and expensive simulations. Therefore, the effectiveness of filters filled with construction waste and biochar is analysed 
using the Kriging method with distance matrices which requires only experimental data and enable us to avoid complicated mathematical modelling by difference-differential equations [15]. The developed method allows modelling filter characteristics with different filler ratios based on the previous experimental studies of filters.

This paper aims to create the methodology and analysis results for investigation and mathematical modelling of filtration properties of surface wastewater filters.

\section{Methods and materials}

Operation of filters is based on the absorption of fixed particles of solids (rock wool, aerated concrete and biochar). In the case of surface wastewater flowing through an experimental surface water test bench, an aerobic microorganism film (biological film) may be formed on the fillers.

Sorbents (absorbents and adsorbents) are characterised by specific physical and/or chemical properties that allow sorbents to absorb certain fluids or gases. The principle of absorbent and adsorbent differs slightly: absorbents are materials that absorb particles into the material, while adsorbents are materials on the surface of which sorption takes place. The two processes described here allow absorbing certain substances by concentrating them or removing them from a solution. Thus, sorbents help to remove easily certain pollutants. Sorbents are highly porous materials that can absorb large quantities of pollutants; therefore, they are very important for the treatment of surface wastewater [16]. Properties of the ideal filler for the removal of heavy metals are oleophilicity and hydrophobicity, high sorption capacity, buoyancy, cheapness and availability [17]. Sorbents can be divided into three main categories: natural organic, natural inorganic and synthetic.

In the course of experimental research, filter fillers are composed of the following construction waste: stone wool, aerated concrete and laboratory produced pine wood waste biochar.

\section{Aerated concrete fillers}

One of the main purposes of aerated concrete in filter fillers is to create conditions for aeration. Wastewater that flows through the aerated concrete becomes saturated with oxygen.

\section{Stone wool fillers}

Stone wool is characterised by high water absorption, good air permeability and ability to maintain its structure and shape over time. Due to these properties, it is suitable both for the removal of mechanically filtered suspended matter, and biological filtration - removal of organic and nitrogen pollutants. Compared to the aerated concrete filler, the stone wool hydraulic permeability is much lower, therefore, it could fill existing gaps between activated concrete and biochar in a surface wastewater filter, thus reducing the rate of filtered surface wastewater.

Stone wool, used for experimental research, was derived from construction waste, due to the relatively low cost and while trying to increase possibilities for reuse of waste. Stone wool cubes of the same size $(20 \times 20 \mathrm{~mm})$ were used for filling the filtration layer.

Prior to the experimental studies all filtering materials were flushed 3 times with distilled water. 


\section{Biochar fillers}

The use of biochar for surface wastewater treatment is a topical subject of today's research. Taking into account biochar properties such as water absorption, the sorption of pollutants (heavy metals: $\mathrm{Cd}, \mathrm{Pb}, \mathrm{Zn}, \mathrm{Cu}, \mathrm{Ni}$ and $\mathrm{Hg}$; pesticides) can be used for surface wastewater treatment [18-22]. Schmidt argues that biochar is able to absorb water weights as high as 6 times its own [23].

Biochar was made using pyrolysis. The biochar from pine wood waste was produced under following conditions: $450 \pm 5^{\circ} \mathrm{C}$ for $120 \mathrm{~min}$ (slow pyrolysis).

\section{Description of filtration unit}

A test bench, the principal scheme of which is shown in Figure 1, was used.

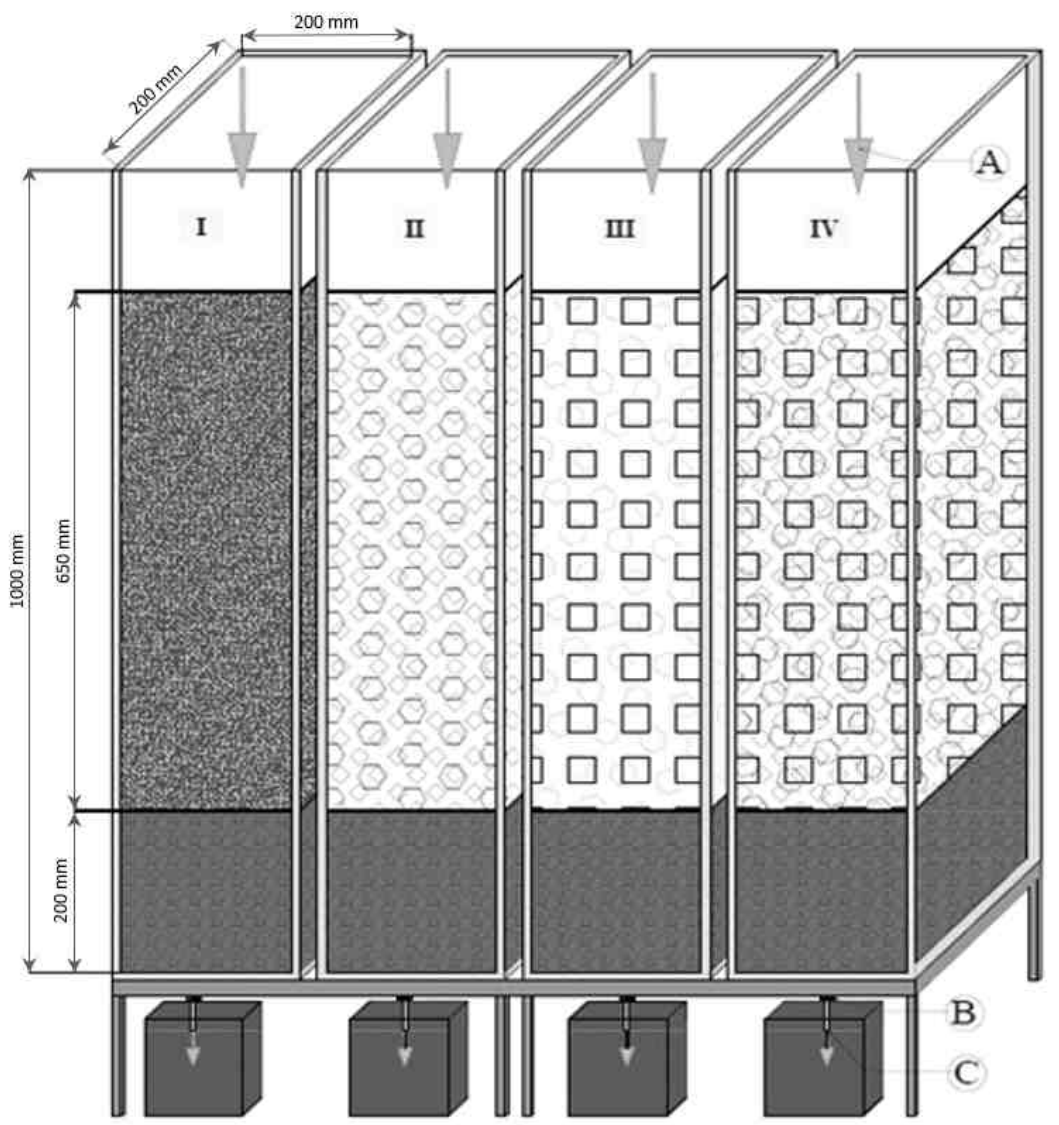

Fig. 1. Surface wastewater filtration test bench with different fillers: A - surface wastewater supply; B - water valve; C - drainage of surface wastewater after filtration; I - quartz sand; II - rock wool (bulk volume proportion 2/3) and aerated concrete (bulk volume proportion 1/3); III - aerated concrete (bulk volume proportion 2/3) and biochar (bulk volume proportion 1/3); IV - rock wool (bulk volume proportion 1/3), aerated concrete (bulk volume proportion 1/3) and biochar (bulk volume proportion 1/3) 
The same amount of surface wastewater was supplied to filters with different fillers. Valves made of filters were installed to control the surface wastewater flow. In order to have wastewater evenly distributed over the entire surface of filter filler, a feedstart mesh was fitted, and in order to prevent the penetration of fillers into the filtrate, a supporting drainage layer was installed on the bottom of the filtration cylinder.

\section{Methods for heavy metal detection}

Heavy metals: $\mathrm{Zn}, \mathrm{Cd}, \mathrm{Cu}$ and $\mathrm{Pb}$ were determined by atomic absorption spectrometry using the Buck Scientific Model 210 VGP Atomic Absorption Spectrometer. Wavelength: $\mathrm{Cu}$ - $324.7 \mathrm{~nm} ; \mathrm{Cd}-228.8 \mathrm{~nm} ; \mathrm{Zn}$ - $213.9 \mathrm{~nm} ; \mathrm{Pb}$ - $283.2 \mathrm{~nm}$.

\section{Determination of suspended solids (SS)}

Suspended solids were determined using a DURAN filtering apparatus. Suspended solids were determined as follows: vacuum was applied and filtering through a glass fibre filter $(0.45 \mu \mathrm{m})$ placed in the funnel was carried out. After filtration, the filter was dried $\left(105 \pm 2{ }^{\circ} \mathrm{C}\right)$ to constant weight and weighed, thus determining the weight of the precipitate retained on the filter.

\section{Determination of organic carbon and total nitrogen}

Total carbon and nitrogen were determined using a Shimadzu TOC-V CSV series total organic carbon analyser.

\section{Biochemical oxygen demand $\left(\mathrm{BOD}_{5}\right)$}

Biochemical oxygen consumption in surface wastewater BOD was determined with VELP Scientifica Sensor System $\left(\mathrm{BOD}_{5}\right.$ at $\left.20{ }^{\circ} \mathrm{C}\right)$. Measurement range was up to $999 \mathrm{mg} / \mathrm{dm}^{3}$.

\section{Statistical processing of results}

The results of surface wastewater filtration through different filter fillers were statistically processed (sample standard deviation was calculated) by eliminating unreliable values.

\section{Quality assurance}

Standard solutions of $\mathrm{Cu}, \mathrm{Cd}, \mathrm{Pb}$ and $\mathrm{Zn}(1000 \mathrm{ppm})$ were used for Atomic Absorption Spectrometer calibration. All the chemicals used in this study were of analytical grade and solutions were prepared with deionized water. Deionized water prepared by DEMIWA 3 ROI was used for the preparation of all solutions $(<0.05 \mu \mathrm{S} / \mathrm{cm}$, ISO 3696:1987 [24]). In order to monitor for possible contaminations resulting from the sample preparation procedure, a reagent blank was prepared for each of the digestion procedure.

\section{Mathematical modelling of effectiveness of surface wastewater treatment filter fillers}

Surface wastewater treatment filters are one of the technologies, capable of reducing suspended solids, heavy metals and other pollutants. Let us analyse the effectiveness of filters filled with construction waste and biochar using multidimensional data, obtained by 
measuring of filters with different fillers. Note that, computational models applied in the environment engineering sometimes require to fulfil expensive simulations. In these cases, the Kriging method is proposed to increase the efficiency of solving modelling, prediction and optimization problems [25, 26]. Since the Kriging method was developed as a consequence of its accurate predictions, it became one of the most promising numerical approaches in the various fields of engineering design, spatial statistics, experiment design, and so on $[15,26]$. In general, Kriging is a method of interpolation for which the interpolated values are modelled by a multivariate Gaussian process, governed by prior covariances. The basic idea of Kriging is to predict the value of a response function at a given point by computing a weighted average of the known values of this function in the neighbourhood of the point. Thus, Kriging gives a way of anticipating, with some probability, a result associated with values of the parameters that have never been met before using the existing information (e.g., the experimental measurements).

Let us consider the approach to measurement data modelling by the Gaussian Random field, using geometrical properties of fractional Euclidean distance matrices [15]. The developed model allows us to represent the information, obtained from any number of measurements of the response function by a computational code or physical experiment. The resulting model is rather simple and depends on a small set of parameters that are efficiently estimated by the Maximal Likelihood method.

Let $x=\left(x_{1}, x_{2}, x_{3}, x_{4}\right)^{T}$ be filler ratios vector, where $x_{1}$ - quartz sand (QS), $x_{2}$ - shredded autoclaved aerated concrete (SHAAC), $x_{3}$ - stone wool (SW), $x_{4}$ - biochar (BC). Denote the vector of results of filter characteristics measurement: $Y_{i}^{j}, 1 \leq i \leq m$, where $K=4$ - number of experiments, and $m$ - number of filter characteristics. Assume these filter characteristics be describing capability to treat different wastes. These filters with different fillers are designed for treatment of main pollutants of surface wastewater by heavy metals (zinc $(\mathrm{Zn})$, cadmium $(\mathrm{Cd})$, copper $(\mathrm{Cu})$, lead $(\mathrm{Pb})$ ) and by total nitrogen $(\mathrm{TN})$, total carbon (TC), suspended solid $(S S)$, biochemical oxygen demand $\left(\mathrm{BOD}_{5}\right)$.

Filter fillers:

1 - Quartz sand (100\%);

2 - Shredded autoclaved aerated concrete $(66.7 \%)$ and stone wool $(33.3 \%)$;

3 - Shredded autoclaved aerated concrete $(33.3 \%)$ and biochar $(66.7 \%)$;

4 - Shredded autoclaved aerated concrete $(33.3 \%)$, biochar $(33.3 \%)$ and stone wool $(33.3 \%)$.

Thus, the experiment matrix of filler proportions [\%] is as follows:

$$
X=\left|\begin{array}{cccc}
1 & 0 & 0 & 0 \\
0 & 0.667 & 0 & 0.333 \\
0 & 0 & 0.333 & 0.667 \\
0 & 0.333 & 0.333 & 0.333
\end{array}\right|
$$

The filtration characteristic measurement matrix was $Y=\left(Y^{1}, Y^{2}, Y^{3}, Y^{4}\right)^{T}$, where cleaning efficiency are in Table 1. 
Filter cleaning efficiency

Cleaning efficiency [\%]

\begin{tabular}{|c|c|c|c|c|c|c|c|c|}
\hline \multicolumn{8}{|c|}{ Cleaning efficiency [\%] } \\
\hline \multirow{2}{*}{ No. } & Pb & Cd & $\mathbf{Z n}$ & $\mathbf{C u}$ & $\mathbf{T C}$ & $\mathbf{T N}$ & SS & BOD $_{\mathbf{5}}$ \\
\cline { 2 - 9 } & $Y^{1}$ & $Y^{2}$ & $Y^{3}$ & $Y^{4}$ & $Y^{5}$ & $Y^{6}$ & $Y^{7}$ & $Y^{8}$ \\
\hline 1 & 78.0 & 55.1 & 94.7 & 58.5 & 27.3 & 41.1 & 97.2 & 42.1 \\
\hline 2 & 73.7 & 22.2 & 57.2 & 15.2 & 38.3 & 15.6 & 94.1 & 43.4 \\
\hline 3 & 75.0 & 43.9 & 77.1 & 20.5 & 50.7 & 17.3 & 94.1 & 58.9 \\
\hline 4 & 77.3 & 47.3 & 81.1 & 28.8 & 43.2 & 19.9 & 93.4 & 60.4 \\
\hline
\end{tabular}

For better evaluation of filter efficiency extrapolation of filter characteristics using experimental results is necessary. In this paper, the Kriging method with distance matrices based on experimental data is proposed to apply for this purpose, because it enables data modelling and extrapolation using only a small experimental sample [27, 28]. Denote matrix of Euclidean distance between pairs of experimental points: 7 .

Denote matrix of Euclidean distance between pairs of experimental points:

$$
A=\left[\sqrt{\left(x_{i, 1}-x_{j, 1}\right)^{2}+\left(x_{i, 2}-x_{j, 2}\right)^{2}+\left(x_{i, 3}-x_{j, 3}\right)^{2}+\left(x_{i, 4}-x_{j, 4}\right)^{2}}\right]_{i, j=1}^{K}
$$

as well as the vector of the chosen extrapolation point $x=\left(x_{1}, x_{2}, x_{3}, x_{4}\right)$ to the experimental points:

$$
\tau_{i}(x)=\sqrt{\left(X_{i, 1}-x_{1}\right)^{2}+\left(X_{i, 2}-x_{2}\right)^{2}+\left(X_{i, 3}-x_{3}\right)^{2}+\left(X_{i, 4}-x_{4}\right)^{2}}
$$

Then the extrapolator is given by the expression $[27,28]$ :

$$
y(x)=Y^{T} \cdot A^{-1} \cdot\left(\tau(x)-E \cdot \frac{E^{T} \cdot A^{-1} \cdot \tau(x)-1}{E^{T} \cdot A^{-1} \cdot E}\right)
$$

According to the model considered the extrapolated value is distributed normally with mean (4) and variance [28]:

$$
s^{2}(x)=d^{2} \cdot\left(\tau(x)^{T} \cdot A^{-1} \cdot \tau(x)-\frac{\left(E^{T} \cdot A^{-1} \cdot \tau(x)-1\right)^{2}}{E^{T} \cdot A^{-1} \cdot E}\right)
$$

where:

$$
d^{2}=\frac{1}{K} \cdot\left(Y^{T} \cdot A^{-1} \cdot Y-\frac{\left(Y^{T} \cdot A^{-1} \cdot E\right)^{2}}{E^{T} \cdot A^{-1} \cdot E}\right)
$$

Visualization of cleaning efficiency using the Kriging approach proposed is given in Figure 2. 


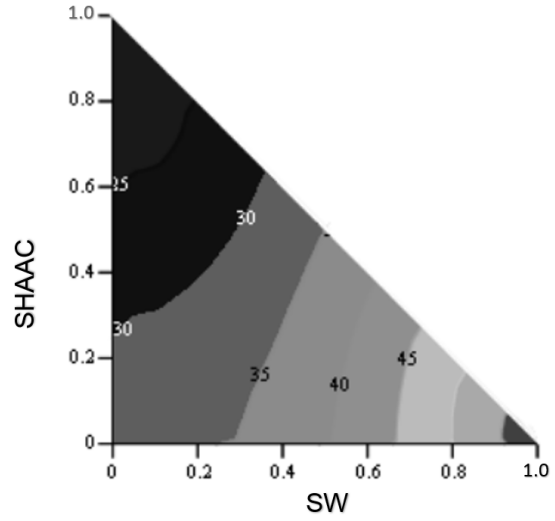

Fig. 2. Cleaning capacity $[\%]$ of copper. Quartz sand $=0$

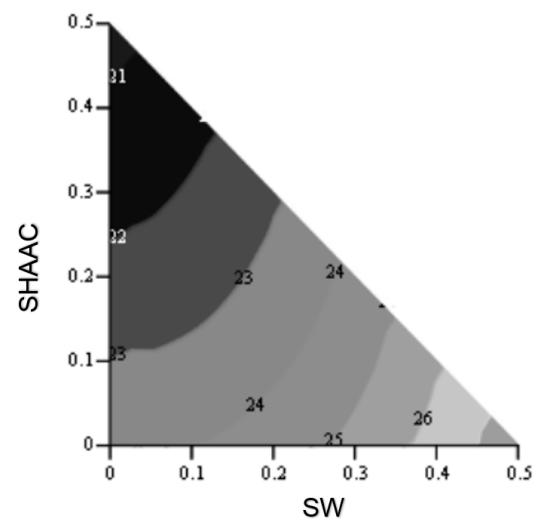

Fig. 3. Cleaning capacity $[\%]$ of copper. Quartz sand $=0.5$

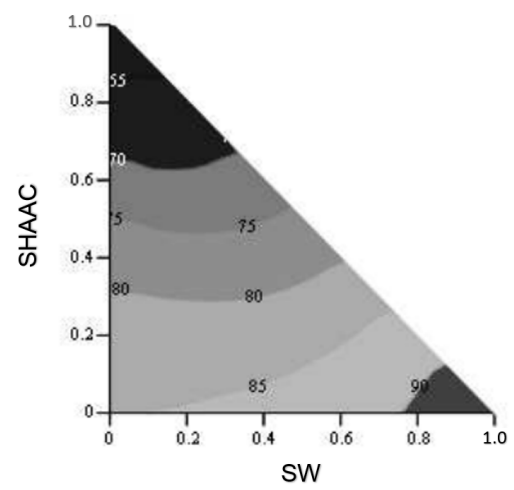

Fig. 4. Cleaning capacity [\%] of zinc. Quartz sand $=0$ 


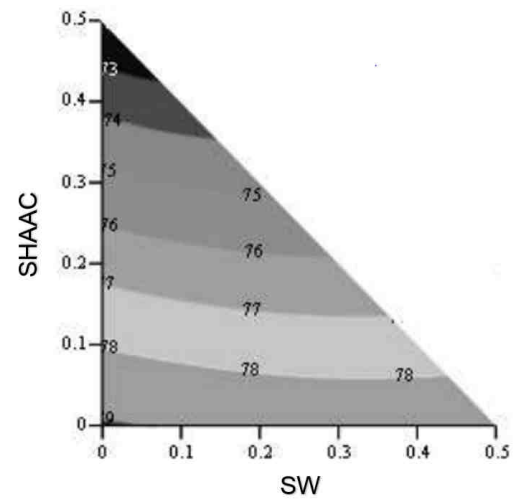

Fig. 5. Cleaning capacity [\%] of zinc. Quartz sand $=0.5$

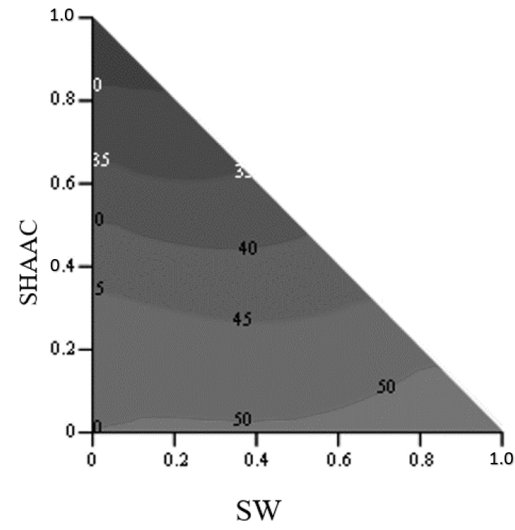

Fig. 6. Cleaning capacity [\%] of cadmium. Quartz sand =0

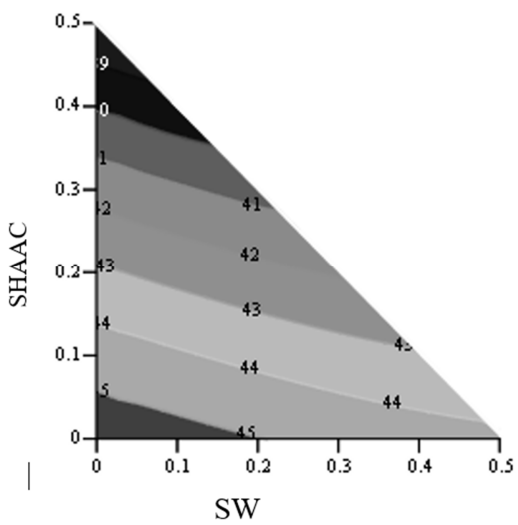

Fig. 7. Cleaning capacity [\%] of cadmium. Quartz sand $=0.5$ 


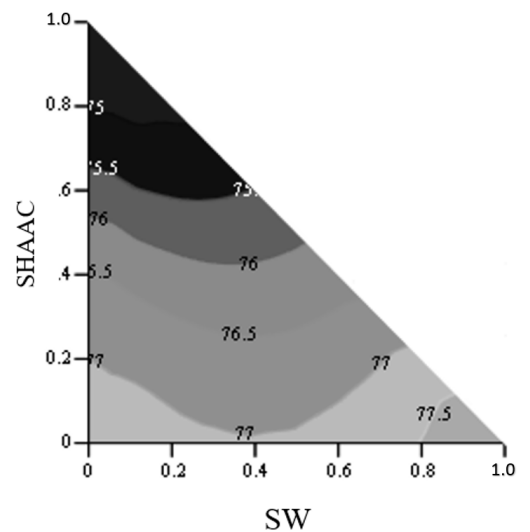

Fig. 8. Cleaning capacity [\%] of lead. Quartz sand $=0$

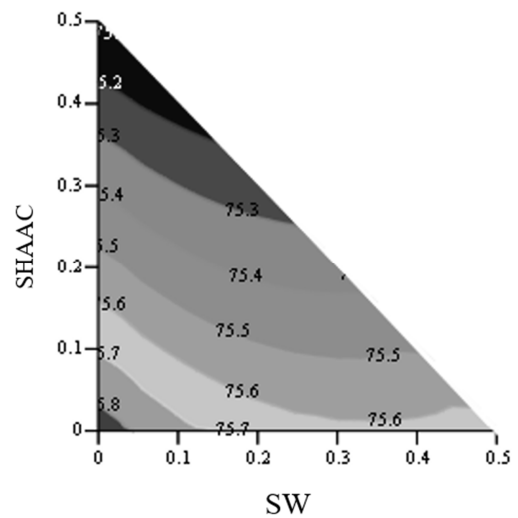

Fig. 9. Cleaning capacity [\%] of lead. Quartz sand $=0.5$

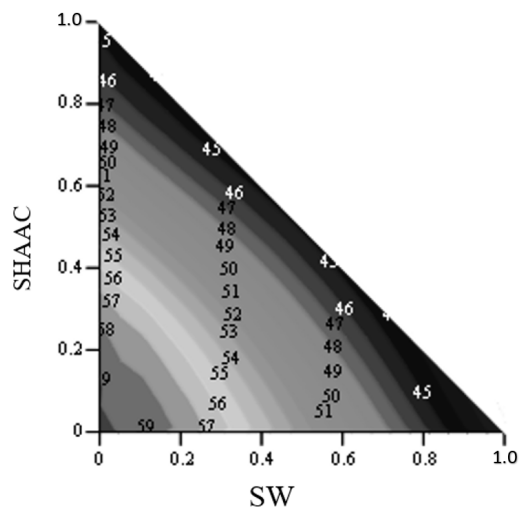

Fig. 10. Cleaning capacity $[\%]$ of $\mathrm{BOD}_{5}$. Quartz sand $=0$ 


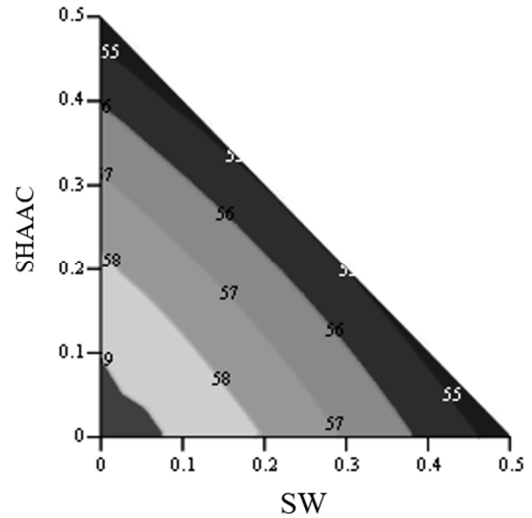

Fig. 11. Cleaning capacity $[\%]$ of $\mathrm{BOD}_{5}$. Quartz sand $=0.5$

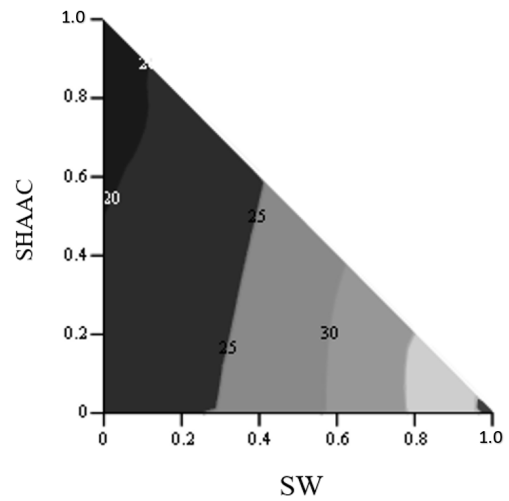

Fig. 12. Cleaning capacity [\%] of total nitrogen. Quartz sand $=0$

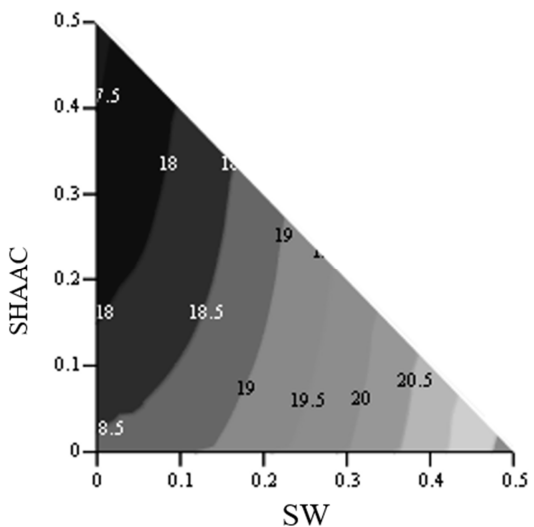

Fig. 13. Cleaning capacity [\%] of total nitrogen. Quartz sand $=0.5$ 


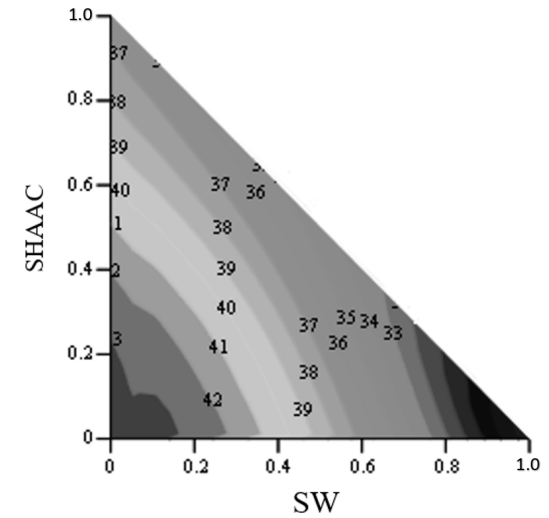

Fig. 14. Cleaning capacity [\%] of total carbon. Quartz sand $=0$

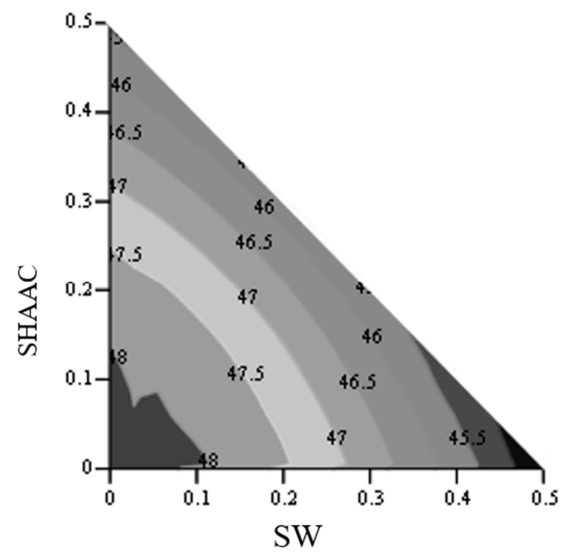

Fig. 15. Cleaning capacity [\%] of total carbon. Quartz sand $=0.5$

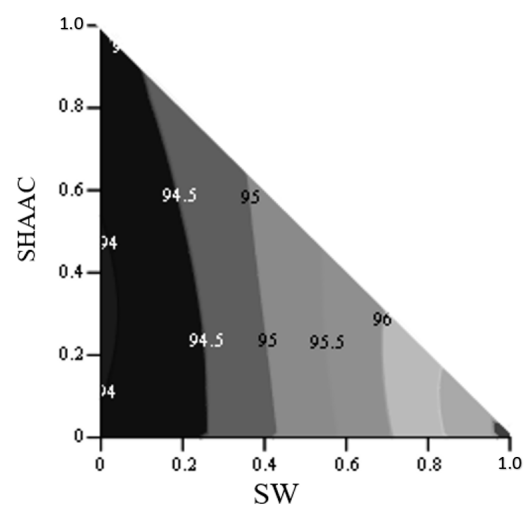

Fig. 16. Cleaning capacity [\%] of suspended solid. Quartz sand $=0$ 


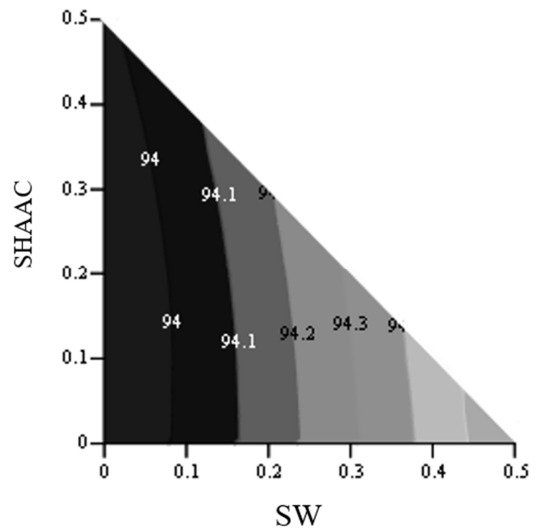

Fig. 17. Cleaning capacity [\%] of suspended solid. Quartz sand $=0.5$

Visualization of the cleaning efficiency [\%] for the fillers proportion $(\mathrm{BC}=1-\mathrm{QS}-\mathrm{SHAAC}-\mathrm{SW})$ using the Kriging approach proposed, is given in Figures 2-17.

The developed extrapolator also was applied for maximization of characteristics by the Monte-Carlo method (1000 trials). Optimal ratios for each characteristic are presented in the Table 2.

Results of filler ratio optimization [\%]

Table 2

\begin{tabular}{|c|c|c|c|c|c|c|c|c|}
\hline \multirow{2}{*}{ Filter filler } & \multirow{2}{*}{ Crit. } & $\mathbf{C u}$ & $\mathbf{Z n}$ & $\mathbf{C d}$ & $\mathbf{P b}$ & $\mathbf{T C}$ & $\mathbf{T N}$ & SS \\
\cline { 3 - 9 } & & $Y^{1}$ & $Y^{2}$ & $Y^{3}$ & $Y^{4}$ & $Y^{5}$ & $Y^{6}$ & $Y^{7}$ \\
\hline $\mathbf{1}$ & $x_{1}$ & 0 & 0.03 & 0.06 & 0.03 & 0.45 & 0.03 & 0 \\
\hline $\mathbf{2}$ & $x_{2}$ & 0 & 0.02 & 0.09 & 0.04 & 0.5 & 0.02 & 0.03 \\
\hline $\mathbf{3}$ & $x_{3}$ & 0.05 & 0.03 & 0.03 & 0.02 & 0.04 & 0.02 & 0.03 \\
\hline $\mathbf{4}$ & $x_{4}$ & 0.95 & 0.92 & 0.82 & 0.91 & 0.01 & 0.93 & 0.94 \\
\hline Extrapolated value & {$[\%]$} & 55.95 & 92.48 & 51.88 & 77.73 & 48.01 & 39.18 & 96.93 \\
\hline
\end{tabular}

As can be seen from Table 2, the created mathematical model allows the optimization of:

- Zinc cleaning efficiency up to $92.48 \%$, the following filter filler ratio is required for this purpose: biochar $92 \%$, stone wool $3 \%$, shredded autoclaved aerated concrete $2 \%$, and quartz sand $3 \%$.

- Lead cleaning efficiency up to $77.73 \%$, the following filter filler ratio is required for this purpose: biochar $91 \%$, stone wool $2 \%$, shredded autoclaved aerated concrete $4 \%$, and quartz sand $3 \%$.

- $\quad$ Suspended solid cleaning efficiency up to $96.93 \%$, the following filter filler ratio is required for this purpose: biochar $94 \%$, stone wool $3 \%$, shredded autoclaved aerated concrete $3 \%$, and quartz sand $0 \%$.

- Cadmium cleaning efficiency up to $51.88 \%$, the following filter filler ratio is required for this purpose: biochar $82 \%$, stone wool $3 \%$, shredded autoclaved aerated concrete $9 \%$, and quartz sand $6 \%$. 
- Total carbon cleaning efficiency up to $48.01 \%$, the following filter filler ratio is required for this purpose: biochar $1 \%$, stone wool $4 \%$, shredded autoclaved aerated concrete $50 \%$, and quartz sand $45 \%$.

- Total nitrogen cleaning efficiency up to $39.18 \%$, the following filter filler ratio is required for this purpose: biochars $93 \%$, stone wool $2 \%$, shredded autoclaved aerated concrete $2 \%$, and quartz sand $3 \%$.

Thus, the developed method allows modelling filter characteristics with different filler ratios based on the previous experimental studies of filters.

\section{Conclusion}

The study carried out on the effectiveness of surface wastewater filter fillers showed that the fillers made of construction waste could remove different pollutants from surface wastewater effectively. The filter filled with quartz sand was the most effective in removing suspended solids from surface wastewater, with the average removal efficiency of $97.2 \%$. The results of total carbon removal from surface wastewater showed that the best result was achieved with the filter of shredded autoclaved aerated concrete and biochar; the efficiency was $50.7 \%$. The highest total nitrogen removal efficiency was achieved with the quartz sand filter $-41.1 \%$. Having performed experimental studies on the efficiency of heavy metal removal, the results showed that the most effective filters for removing heavy metals $(\mathrm{Pb}, \mathrm{Cd}, \mathrm{Zn}$ and $\mathrm{Cu})$ were the quartz sand filter, and the one composed of shredded autoclaved aerated concrete, biochar and stone wool. The filter made of shredded autoclaved aerated concrete, biochar and stone wool removed $\mathrm{BOD}_{5}$ most effectively as well, with an efficiency of $60.4 \%$. The experimental results showed that different fillers were differently effective in retaining (removing) different surface wastewater pollutants. Therefore, only mathematical modelling calculations can determine the optimal ratio of fillers in the wastewater treatment filters, thereby increasing the efficiency of pollutant removal in the filters.

The experimental method created and experiments performed allow us to form a mathematical model suitable for extrapolation of filter characteristics. The developed mathematical model is adapted to optimize the cleaning of surface water discharges by calculating optimal filler proportions. Mathcad program is executed in mathematical modelling.

The mathematical model is suitable for other filtrate characteristics, not only the ratio of fillers, but also the length of the filter life, its durability calculations, which allows optimizing filter cleaning efficiency up to $96.93 \%$.

\section{References}

[1] Stec A, Słyś D. Rainwater potential use in dormitory building: drinking water savings and economic costs. Ecol Chem Eng A. 2017;24(1):43-64. DOI: 10.2428/ecea.2017.24(1)4.

[2] Managing Urban Runoff. Available from: http://www.epa.gov/polluted-runoff-nonpoint-source-pollution.

[3] Reddy KR, Xie T, Dastgheibi S. Removal of heavy metals from urban stormwater runoff using different filter materials. J Environ Chem Eng. 2014;2(1):282-92. DOI: 10.1016/j.jece.2013.12.020.

[4] Ghofrani Z, Sposito V, Faggian R. Designing a pond and evaluating its impact upon storm-water quality and flow: A case study in rural Australia. Ecol Chem Eng S. 2019;26(3):475-91. DOI: 10.1515/eces-2019-0036.

[5] Ambrose RF, Winfrey BK. Comparison of stormwater biofiltration systems in Southeast Australia and Southern California. WIREs Water. 2015;2(2):131-46. DOI: 10.1002/wat2.1064.

[6] Stormwater Program. Available from: http://www.epa.gov/npdes/npdes-stormwater-program. 
[7] Claytor RA, Schueler TR. Design of Stormwater Filtering Systems. The Center for Watershed Protection. Ellicott City, MD. 1996; Available from: https://owl.cwp.org/mdocs-posts/design-of-sw-filtering-systems/.

[8] Garzón-Zúñiga MA, Tomasini-Ortíz AC, Moeller-Chavez G, Hornelas-Uribe Y, Buelna G, Mijaylova-Nacheva P. Enhanced pathogen removal in on-site biofiltration systems over organic filtration materials. Water Practice Technol. 2008;3(2): wpt2008053. DOI: 10.2166/wpt.2008.053.

[9] Ilyas A, Muthanna TM. Assessment of upscaling potential of alternative adsorbent materials for highway stormwater treatment in cold climates. Environ Technol. 2017;38(6):705-17. DOI: 10.1080/09593330.2016.1209567.

[10] Lim HS, Lim W, Hu JY, Ziegler A, Ong SL. Comparison of filter media materials for heavy metal removal from urban stormwater runoff using biofiltration systems. J Environ Manage. 2015;147:24-33. DOI: 10.1016/j.jenvman.2014.04.042.

[11] Morgenroth E, Arvin E, Vanrolleghem P. The use of mathematical models in teaching wastewater treatment engineering, Water Sci Technol. 2002;45(6):229-33. DOI: 10.2166/wst.2002.0110.

[12] Novak M, Horvat P. Mathematical modelling and optimisation of a waste water treatment plant by combined oxygen electrode and biological waste water treatment model, Appl Mathematical Modell. 2012;36:3813-25. DOI: 10.1016/j.apm.2011.11.028.

[13] Bomba A, Safonyk A. Mathematical modeling of aerobic wastewater treatment in porous medium. Zesz Nauk Wyższej Szkoły Informatyki. 2013;12(1):21-9. Available from: http://wsinf.edu.pl/assets/img/pdf/Zeszyty\%20naukowe/vol.12/art02.pdf.

[14] Niec J, Spychala M, Zawadzki P. New approach to modelling of sand filter clogging by septic tank effluent, J Ecol Eng. 2016;17(2):97-107. DOI 10.12911/22998993/62296.

[15] Pozniak N, Sakalauskas L, Saltyte L. Kriging Model with Fractional Euclidean Distance Matrices. Informatica. 2019;30(2):367-90. Available from: https://content.iospress.com/articles/informatica/inf 1222.

[16] $\mathrm{Hu}$ J, Chen G, Lo IHC. Selective removal of heavy metals from industrial wastewater using maghemite nanoparticles: Performance and mechanisms. J Environ Eng. 2006;132(7):709-15. DOI: 10.1061/(ASCE)0733-9372(2006)132:7(709).

[17] Zhu Y, Murali S, Stoller MD, Ganesh KJ, Cai W, Ferreira PJ, et al. Carbon-based supercapacitors produced by activation of graphene. Science. 2011;332(6037):1537-41. DOI: 10.1126/science.1200770.

[18] Beck DA, Johnson GR, Spolek GA. Amending greenroof soil with biochar to affect runoff water quantity and quality. Environ Pollut. 2011;159:2111-8. DOI: 10.1016/j.envpol.2011.01.022.

[19] Hina K. Application of biochar technologies to wastewater treatment [PhD]. New Zealand: Massey University; 2013. Available from: https://mro.massey.ac.nz/handle/10179/4288.

[20] Khare P, Dilshad U, Rout PK, Yadav V, Jain S. Plant refuses driven biochar: Application as metal adsorbent from acidic solutions. Arab J Chem. 2013;10:S3054-63. DOI: 10.1016/j.arabjc.2013.11.047.

[21] Regmi P, Moscoso JLG, Kumar S, Cao X, Mao J, Schafran G. Removal of copper and cadmium from aqueous solution using switchgrass biochar produced via hydrothermal carbonization process. J Environ Manage. 2012;106:61-9. DOI: 10.1016/j.jenvman.2012.04.047.

[22] Gnecco I, Berretta C, Lanza LG, La Barbera P. Storm water pollution in the urban environment of Genoa, Italy. Atmosph Res. 2005;77:60-73. DOI: 10.1016/j.atmosres.2004.10.017.

[23] Schmidt HP. 55 uses of biochar. Ithaka J. 2012;1(1):286-9. Available from: https://www.terrapreta.bioenergylists.org/files/e082012-55-uses-of-bc.pdf.

[24] ISO 3696:1987 - Water for analytical laboratory use. Specification and test methods (null water for analytical laboratory use - Specification and test methods). Available from: https://www.iso.org/standard/9169.html.

[25] Jones DR. A taxonomy of global optimization methods based on response surfaces. J Global Optimization. 2001;21(4):345-83. DOI: 10.1023/A:1012771025575.

[26] Carpio R, Giordano RC, Secchi A. Enhanced surrogate assisted global optimization algorithm based on maximizing probability of improvement. Computer Aided Chem Eng. 2017;40:2065-70. DOI: 10.1016/B978-0-444-63965-3.50346-9.

[27] Sakalauskas L. Locally Homogeneous and isotropic Gaussian fields in Kriging. Informatica. 2013;24(2):253-74. Available from: https://www.mii.lt/INFORMATICA/pdf/INFO904.pdf.

[28] Pozniak N, Sakalauskas L. Fractional Euclidean distance matrices extrapolator for scattered data. JMD. 2017;2(47):56-61. DOI: 10.21277/jmd.v47i2.156. 